\title{
A Study on the Exploration of Electrostatic Powder Coating Materials Suitable for 3D Scanning
}

\author{
Hee-young MAENG ${ }^{1}$, Myoungsang LEE ${ }^{2}$ \\ ${ }^{1}$ Seoul National University of Science and Technology, 232 Gongreung-ro, Seoul, Korea \\ ${ }^{2}$ Graduate School of Mechanical Design and Robot Eng., Seoul National Univ. of Science and Technology, Korea
}

\begin{abstract}
There are many difficulty in collecting data from a diffused reflection surface using an optical 3D scanning device. A spray-type developer and silicon molds are used for solving this problem. However, using developer can cause chemical reactions between objects and developer particles and uneven surfaces of the object. To overcome these problems, it is suggested an electrostatic powder coating method for even coating of particles onto surfaces for collecting 3D shape data. We have developed an automatic, electrostatic powder coating machine. The present study is aimed to explore powder materials suitable for electrostatic powder coating in terms of the easiness of coating work considering the characteristics of object surface. It was also conducted to verify materials that are smoothly coated well under various coating conditions and are advantageous in collecting 3D shape data.
\end{abstract}

\section{Introduction}

Recently, as the cultural content industry and the 3D printing industry have been developing, demand for $3 \mathrm{D}$ shape digital information has been increasing day by day and contactless white light scanners and laser scanners have been the most widely utilized in constructing such information. However, whereas contactless 3D scanners that use light or laser are excellent in terms of measuring efficiency and accuracy, they have a demerit in that some of data are not collected from surfaces where irregular reflection or scattering occurs such as glossy metal surfaces, crystal, and ceramics because sensed lights are not properly recognized.

From long ago, indirect measuring methods such as thinly applying a developer before scanning or making silicon molds have been used for such surfaces. However, such methods also have many problems. Additional costs of consumables such as coating agents and solvents are required, working time is lengthened, chemical corrosion may occur, and materials used are harmful to human bodies. In addition, coating thicknesses cannot be easily made uniform because developers or coating agents flow down because of the nature of liquids, form accuracy is deteriorated because liquids infiltrate into cracks or sharp grooves and harden there, and removing the hardened liquids after work requires great effort.

To solve these problems, a device that can easily coat or remove developers while reducing coating thicknesses by introducing the principle of electrostatic powder coating was developed in the previous study. The fact that 3D scanning sensitivity improved remarkably on electrostatic powder coated object surfaces and the form accuracy of collected data became more excellent was identified through experiments.

The present study is a follow-up study of the previous study and aimed to explore powder materials suitable for electrostatic powder coating in terms of the easiness of coating work considering the characteristics of object surface. The present study was also conducted to verify materials that are smoothly coated well under various coating conditions and are advantageous in collecting 3D shape data and to accumulate the results in order to utilize them as practical technical data.

\section{Electro-static powder coating}

An electrostatic powder coating method is a coating method that uses static electricity. In the present, an electrostatic powder coating method was designed that would mix the powder and compressed air in the storage tank and spray the mixture using the high pressure in the spray tube. The powder tank was designed so that corona discharge would occur if anodic high voltage was applied to the powder in the powder tank to make the coating agent have the characteristics of an anode and the object to be coated would be grounded to enable the currents to escape so that only a negative electric charge would remain on the product. When preparation for conduction of static electricity has been completed, high pressure 
compressed air and fine powder would be sprayed through the spray gun.

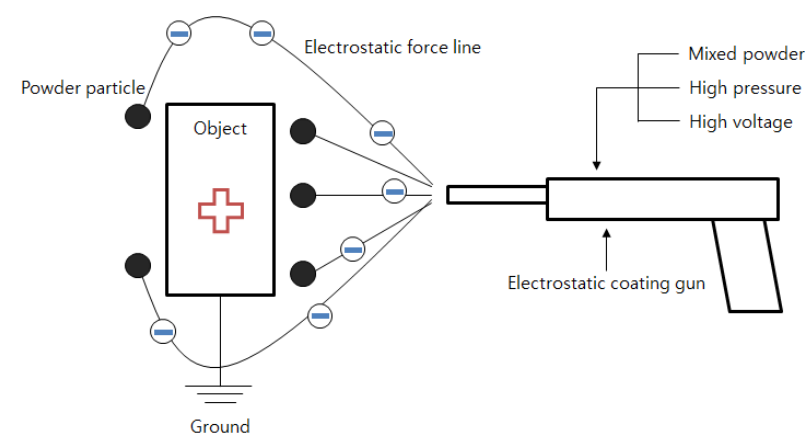

(a) Schematic principle

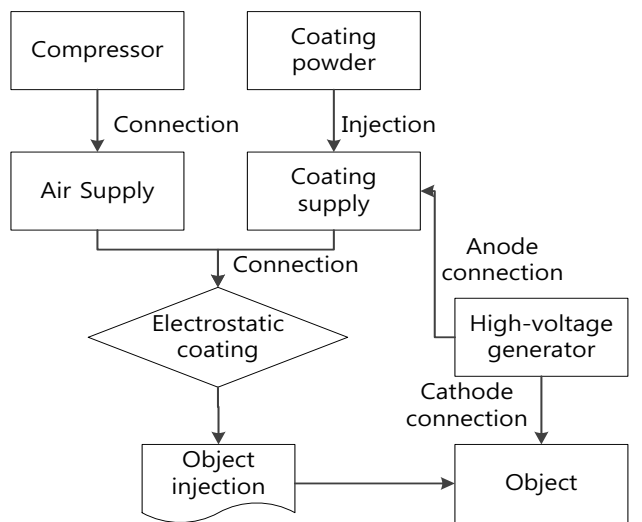

(b) Process diagram of spray coating

Figure 1. Principle of electrostatic powder coating

A great advantage of this method is that the uniformity of the surface is enhanced because the sprayed particles generate repulsive force against each other so that the coating thickness does not increase over a certain thickness. Major factors that affect coating include applied voltage, the properties of powder particles, spraying distance, air pressure, and time.

The electrostatic powder coating equipment was constructed with a powder spray unit, a powder removal unit, a powder collection unit, an object fixing table, and a controller as shown in Figure 2 and the system operation process was designed so that the system is controlled as shown in the flow chart in Figure 3.

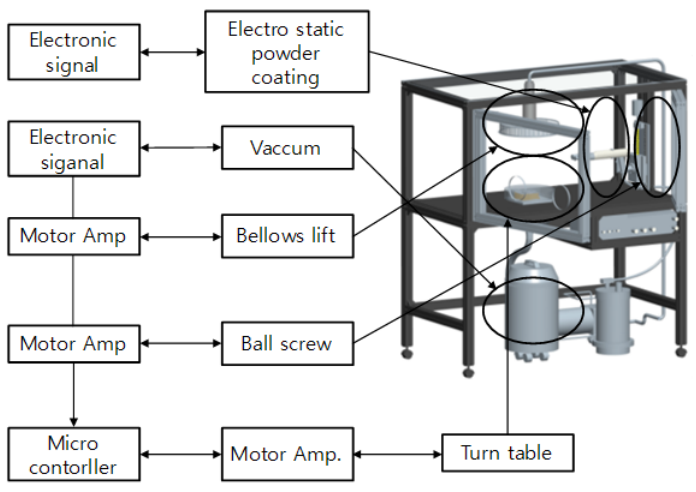

Figure 2. Electro-static powder coating equipment

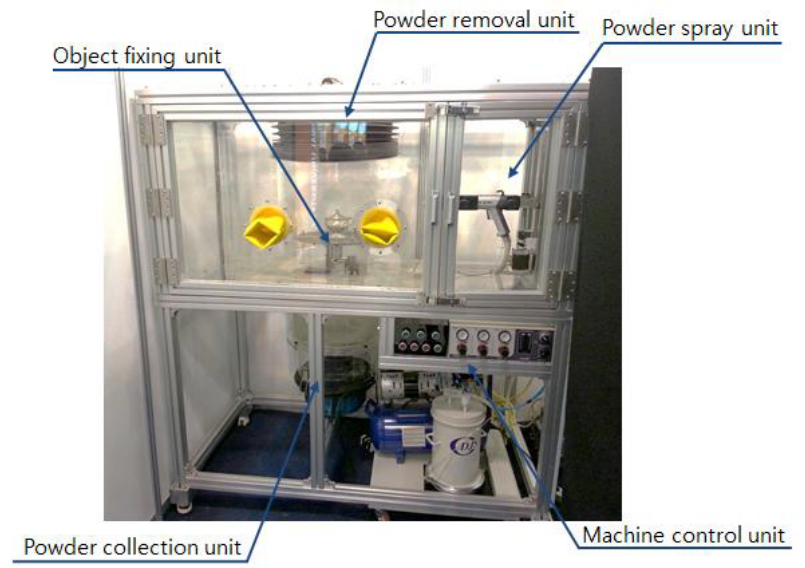

Figure 3. Manufactured coating equipment

The powder spray unit was designed so that it can spray powder while moving up and down as shown in Figure 4 . The shaking of the coating gun was minimized using ball screws and LM guides to enable accurate movements and a brush type shield was installed at the end of the spray unit to prevent the powder from coming into the inside. The powder removal unit was designed so that it can cover the object while moving up and down using a bellows that can cover the air nozzle, the object, and the turn table as shown in Figure 3 with a view to reducing the spatial range of dust flying when the dust on the coated object is removed while increasing the air pressure.

In addition, the powder collection unit was designed to have $6 \mathrm{~mm}$ holes at the outer region of the turn table as shown in Figure 4 so that powder can easily go into the storage tank and a filtering unit was placed in the middle so that the powder can pass through it to be ultimately collected in the powder storage tank and reused.

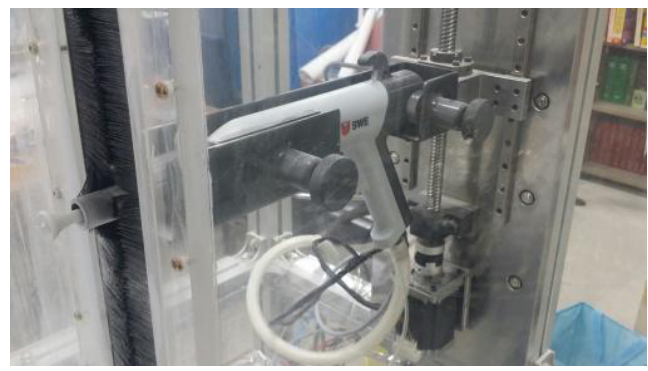

(a) External configuration of spray gun

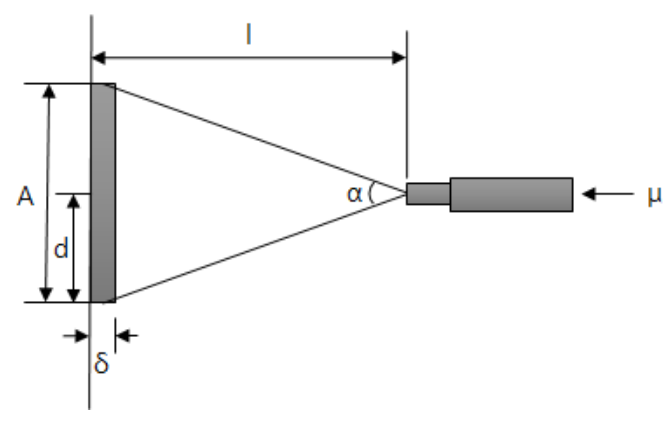

(b) Coating parameters

Figure 4. Powder spray coating by moving air gun 


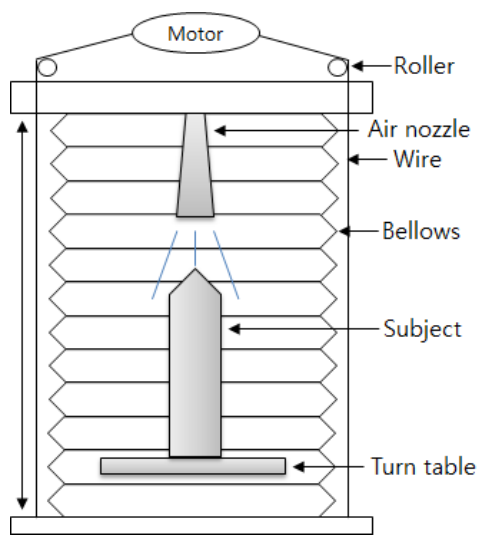

Figure 5. Powder collection unit by bellows suit

\section{Experimental equipment and method}

In the present experiment, the following experimental equipment and method were utilized to explore coating powders suitable for the materials of objects.

\subsection{Experimental equipment}

All samples were made into $3 \mathrm{~cm} \times 3 \mathrm{~cm}$ sizes and the surfaces were finished to be smooth. The samples were composed of a total of seven different materials including metal, wood, nonconductor, plastic, and organic matter. As metals, aluminum and brass that are the most widely used were selected. In the case of wood, plywood was selected. In the case of nonconducting materials, rubber and glass for which electrostatic powder coating is relatively difficult were selected. In the case of plastic, acryl was selected as a representative one and in the case of organic matter, dried pollack was selected.

Meanwhile, the powders applied to the experiment were a total of five different materials. One type of white polyester powder, one type of white epoxy powder, and one type of gray polyester-epoxy powder were selected and as powders which are not harmful, one type of medium wheat flour and one type of baby powder which are not chemical materials were selected. All samples were placed perpendicularly to the coating gun and the coating gun's spray pressure and distance were applied identically to all samples.

\subsection{Experimental method}

In the present experiment, six different materials were coated with five different powders using the device. The coated surfaces were checked using a 3D Video Measuring System(VMS-1510F) to determine coating grades. All experimental conditions were maintained the same and the same experiment was repeated three times to determine average grades. In addition, in the case of materials that could not be coated, methods that would not cause damage to the surface were applied to pre-treat the object before coating.

As a pretreatment method, the objects were covered with water-film coating for convenience in use and to keep the surfaces harmless. As for the pretreatment process, the objects were kept in the cold room of a refrigerator with a capacity not lower than $11.9 \mathrm{kWh} /$ month for 10 minutes before being coated and the coating time for each objects did not exceed 10 minutes.

\section{Experimental results and discussion}

The results of exploration of powders suitable for conductive materials are as shown in Table 1. Although aluminum was well coated by all powders and the coating was well removed because aluminum is a conductor, it was identified that among the powders, polyester powder was evenly coated without any phenomenon of lumping.

In the case of brass, hybrid coating materials and epoxy were evenly coating without forming any particular pattern on the surface but other powders were identified as being unsuitable as they had certain patterns of were not coated well on edges.

Meanwhile, in the case of wood, particles may remain after removing powders to cause damage to the product because wood has textures. In the present experiment, epoxy powder was found remaining on the surface of the samples because its particles are finer than those of polyester and in the case of wheat flour and baby powder, some particles lumped. Therefore, the most suitable powder for objects made of wood can be said to be polyester.

When the object was organic matter, all powders were well coated and removed because the surface was coarse and conductive. However, since polymer powders consisting of chemical materials cause damage to object surfaces, using organic powder is recommended and powder materials in finer particles should be better.

Table 1. Coating and removal grade after experiment

\begin{tabular}{|c|c|c|c|c|c|c|}
\hline \multicolumn{2}{|r|}{ Process type } & Polyester & Polyes.epox & ероху & wheat & powder \\
\hline \multirow{6}{*}{$\begin{array}{l}\mathrm{C} \\
\mathrm{O} \\
\mathrm{N} \\
\mathrm{D} \\
\mathrm{U} \\
\mathrm{C} \\
\mathrm{T} \\
\mathrm{O} \\
\mathrm{R}\end{array}$} & $\begin{array}{l}\text { Aluminium } \\
\text { coating }\end{array}$ & ๑ & O & O & O & O \\
\hline & $\begin{array}{l}\text { Aluminium } \\
\text { coating } \\
\text { remove }\end{array}$ & ๑ & ๑ & ๑ & O & ๑ \\
\hline & Brass coating & $\Delta$ & ๑ & ๑ & O & O \\
\hline & $\begin{array}{c}\text { Brass coating } \\
\text { remove }\end{array}$ & ๑ & $\odot$ & ๑ & ๑ & ๑ \\
\hline & Wood coating & ๑ & ๑ & O & O & ๑ \\
\hline & $\begin{array}{c}\text { Wood coating } \\
\text { remove }\end{array}$ & ○ & O & $\Delta$ & $\Delta$ & $\Delta$ \\
\hline \multirow{2}{*}{$\begin{array}{l}\mathrm{O} \\
\mathrm{R} \\
\mathrm{G} \\
\mathrm{A} \\
\mathrm{N}\end{array}$} & $\begin{array}{c}\text { Dried pollack } \\
\text { coating }\end{array}$ & O & O & O & ๑ & ๑ \\
\hline & $\begin{array}{c}\text { Dried pollack } \\
\text { coating } \\
\text { remove }\end{array}$ & O & O & O & ○ & ๑ \\
\hline
\end{tabular}




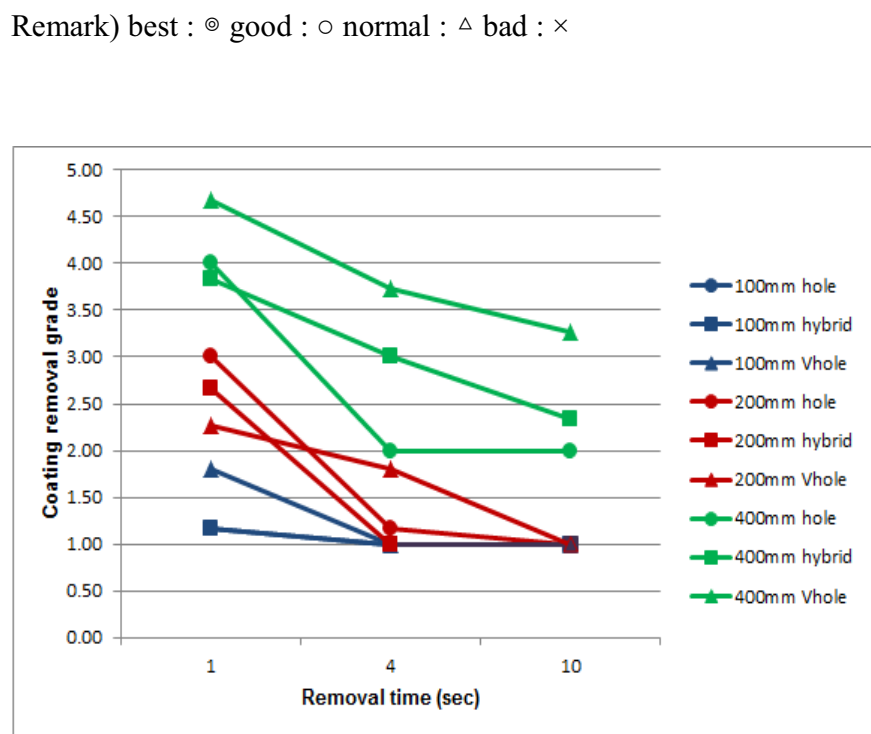

Figure 6. Coating removal grade w.r.t. test-piece state

In the case of objects made of rubber, glass, or acryl that are nonconductors, only some powders were attached by electrostatic powder coating only without pretreatment of the surfaces and in particular, almost no powder was attached to glass.

However, when the surfaces were pre-treated so that water was absorbed by powders, in the case of rubber, the results of coating using the phenomenon of water films and those using polyester-epoxy powder were the most excellent.

Although rubber was also well coated by polyester, the end areas were not uniformly coated. When the object was glass, coating using wheat flour showed the highest level of surface uniformity.

This is considered attributable to the fact that wheat flour is well electrified because it has moisture and water has an affinity with glass surface.

Table 2. Coating and removal grade after post work

\begin{tabular}{c|c|c|c|c|c}
\hline \hline Coating material & Polyester & $\begin{array}{c}\text { Polyester } \\
\text { epoxy } \\
\text { (hybrid) }\end{array}$ & epoxy & $\begin{array}{c}\text { wheat } \\
\text { flour }\end{array}$ & powder \\
\hline Rubber coating & $\circ$ & $\bigcirc$ & $\times$ & $\Delta$ & $\times$ \\
\hline $\begin{array}{c}\text { Rubber coating } \\
\text { remove }\end{array}$ & $\times$ & $\circ$ & $\Delta$ & $\times$ & $\Delta$ \\
\hline $\begin{array}{c}\text { Glass coating } \\
\text { Glass coating } \\
\text { remove }\end{array}$ & $\Delta$ & $\circ$ & $\Delta$ & $\bigcirc$ & $\Delta$ \\
\hline $\begin{array}{c}\text { Acrylic coating } \\
\text { Acrylic coating } \\
\text { remove }\end{array}$ & $\Delta$ & $\circ$ & $\times$ & $\Delta$ & $\times$ \\
\hline Rematk) & 0 & $\bigcirc$ & $\Delta$ & $\bigcirc$ \\
\hline
\end{tabular}

Remark) best : $\odot$ good : $\odot$ normal : $\triangle$ bad : $\times$

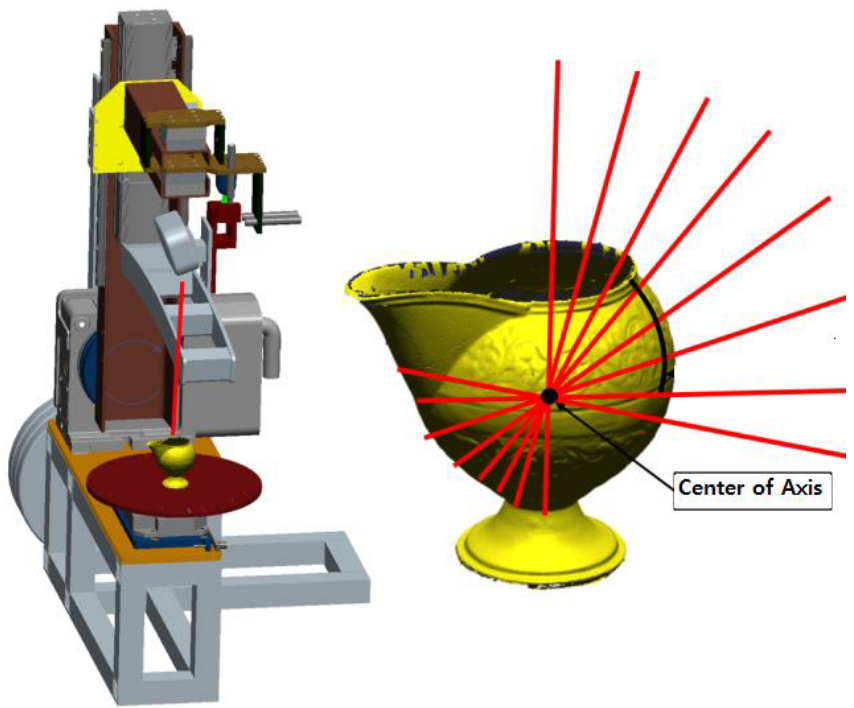

Figure 7. Data acquisition test by 3D scanning devices

\section{Conclusion}

An automated equipment unit that coats powder and remove the coating using electrostatic powder coating devices was developed and to show the excellence of the equipment unit, coating efficiency, coating removal efficiency, and coating materials were examined.

In the process of conducting the present study, the following facts could be found. Firstly, it is evaluated the closest relationships between with the distances and time of spray gun. Whereas conductive materials were evenly coated regardless of the types of powder, nonconductive materials were not easily coated and could be coated through pretreatment. Although aluminum was well coated by all powders and the coating, it was identified that polyester powder was evenly coated without any phenomenon of lumping. In the case of brass, hybrid coating materials and epoxy were evenly coating without forming any particular pattern on the surface. Iin the case of wood, particles may remain after removing powders to cause damage to the product because wood has textures. In the epoxy powder, it was found its particles are finer than those of polyester and in the case of wheat flour and baby powder, some particles lumped.

So that, the most suitable powder for objects made of wood can be said to be polyester. When the object was organic matter, all powders were well coated and removed because the surface was coarse and conductive. In the case of objects made of rubber, glass, or acryl, only some powders were attached by electrostatic powder coating, on the other hand, when the object was glass, it is found that coating using wheat flour showed the highest level of surface uniformity. 


\section{Acknowledgement}

This research was supported by "Archives Preservation Technology R\&D Program" funded by the National Archives of Korea (NAK).

\section{References}

1. H. Maeng, B. Sung., "Development of 3D Measuring System using Spherical Coordinate Mechanism by Point Laser Sensor", Journal of the KSMTE, Vol. 19, No. 4, pp. 427 433 (2004)

2. D. S. Sin, "Study on Ignition Hazards for Electrostatic Discharge of Coating Powder",
Doctorate Thesis, Seoul National Univ. of Science and Technology, Republic of Korea.(2008)

3. C. Lee, S. W. Cha, and K. I. Ho, "Develop-ment of the Rotary Electrostatic Painting Equipment with High Transfer Efficiency," Korean Society for Fluid Machinery, Vol. 7, No. 5, pp. 7 14.(2004)

4. H. T. Kwon, S. M. Baik, and J. Kim, "Synthesis of Doped Ceria Powders by Citrate Method and Their Thin Film Preparation by Electro-spray Method," Appl. Chem. Eng., Vol. 21, No. 1, pp. 76-80.(2010). 